\title{
PRODUÇÃO DE SEMENTES DE CEBOLA EM SISTEMAS CONVENCIONAL E DE TRANSIÇÃO AGROECOLÓGICA ${ }^{1}$
}

\author{
ADRIANA PAULA D'AGOSTINI CONTREIRAS RODRIGUES², CLAUSE FÁTIMA DE BRUM PIANA³, \\ SILMAR TEICHERT PESKE ${ }^{4}$, ORLANDO ANTÔNIO LUCCA FILHO ${ }^{5}$, FRANCISCO AMARAL VILLELA ${ }^{5}$
}

\begin{abstract}
RESUMO - O presente trabalho teve como objetivo fazer um estudo nos sistemas de produção de semente de cebola convencional e agroecológico. Foram acompanhadas três propriedades nos municípios de Candiota e Hulha Negra, RS, de produção agroecológicas e duas convencionais, sendo marcadas aleatoriamente seis unidades de amostragem, cada uma delas com dois metros sobre a linha de produção, em cada uma das propriedades. As variáveis estudadas foram peso de bulbo, diâmetro bulbo quantidade de bulbos por área, quantidade de hastes por bulbo, quantidade de flores por umbela, quantidade de sementes por flor, teor de água da semente, rendimento de sementes, germinação, primeira contagem, peso de 1000 sementes, envelhecimento acelerado, índice e velocidade de germinação e sanidade de sementes, bem como o levantamento dos custos de produção. A produção de semente de cebola através do sistema de produção agroecológico é economicamente viável e ecologicamente sustentável. A produção de semente de cebola em sistema convencional situa-se em média de $30 \%$ do seu potencial. O potencial de produção e qualidade fisiológica da semente de cebola agroecológica e convencional são similares. A variável número de flores por umbela pode ser considerada o componente principal da produção de semente de cebola.
\end{abstract}

Termos para indexação: Allium cepa, sementes de hortaliças, produção agroecológicas.

\section{ONION SEED PRODUCTION IN CONVENTIONAL AND TRANSISTION AGROECOLOGICALSYSTEMS}

\begin{abstract}
BSTRACT - The present work had the objective to study conventional and agroecological systems of onion seed production. For this, three farms with agroecological production and two conventional farmsin Candiota and Hulha Negra, Rs, were followed. Six sampling plots were randomly marked each one with two meters over the production line. The variables studied were: bulb weight, bulb diameter, bulb number per area, number of stems per bulb, number of flowers per umbela, number of seeds per flower, seed moisture content, seed efficiency, germination, first counting, weight of 1000 seeds, accelerated aging, speed of germination seed health. Based on the results the following conclusions were taken: The production of onion seed by the agroecological system is economical possible and ecologically sustainable; onion seed production in conventional systems is less than $30 \%$ of its potential; we can consider that the agroecolgical and conventional production of onion seeds have similar potential and physiologic quality; and the number of flowers per umbela is the main component of onion seed production .
\end{abstract}

Index terms: Allium cepa, vegetables seeds, agroecological production.

\footnotetext{
1 Submetido em 03/02/2007. Aceito para publicação em 04/06/2007.

2 Eng. Agrônoma, Dra ${ }^{a}$, Prof ${ }^{a}$. do Programa de Mestrado Profissional em Produção e Gestão Agroindustrial da Universidade para o Desenvolvimento do Estado e da Região do Pantanal - UNIDERP - Cx. Postal 2153 - Rua Ceará, 333 - Bairro Miguel Couto - Campo Grande/MS - CEP 79003 010 - adricontreiras@ hotmail.com;

3 Bióloga, Mestre, estudante de Doutorado do Curso de Pós-Graduação em Agronomia/ Fitomelhoramento, UFPel - Pelotas, RS;

4 Eng. Agrônomo, Ph.D., Prof. Titular. Departamento de Fitotecnia/FAEM/UFPel.

5 Professor Associado do Depto. de Fitotecnia - FAEM/UFPel
} 


\section{INTRODUÇÃO}

A cebola (Allium cepa L.) é a mais importante entre as espécies cultivadas da família Alliaceae, considerando essencialmente o volume e o valor econômico de seus bulbos (Castellane et al., 1990).

O Rio Grande do Sul responde por cerca de $18 \%$ da produção nacional, o que faz da cebola a segunda hortaliça em importância econômica no estado, e a terceira no país (ICEPA-SC, 2005). Seu cultivo foi introduzido no Brasil pelos açorianos, no século XVIII, nos municípios de Mostardas, Rio Grande e São José do Norte no Estado do Rio Grande do Sul (Garcia, 1990). Em razão da mão-deobra necessária, também tem grande relevância social.

Seu cultivo para produção de sementes, na fronteira sudoeste do Rio Grande do Sul, teve início há mais de 30 anos. Essa região é considerada privilegiada para o cultivo por apresentar condições de solo e clima propícios, principalmente em relação a fotoperíodo, temperatura e umidade. O estado é responsável por $90 \%$ da produção nacional e, desse porcentual, $40 \%$ a $50 \%$ são produzidos nessa região (Sampaio et al., 1998). De acordo com os mesmos autores, a produtividade média (350 kg/ha) de sementes de cebola na região alcança índice superior ao de Minas Gerais (290 kg/ha), conforme Lorenzon \& Martinho (1994).

A cultura da cebola para produção de bulbos, como também para produção de sementes era tradicionalmente feita através do sistema convencional. No final dos anos 80, com a chegada e o assentamento na região sudoeste do RS de colonos vindos de diversas partes do estado, foi introduzida uma nova proposta na agricultura, como alternativa ao padrão produtivo agrícola convencional. Tal proposta enfatizava a viabilidade econômica dos assentamentos, centrada em um amplo conjunto de medidas alternativas.

Sabe-se que o núcleo, por excelência, da produção sustentável é a agricultura familiar. No Brasil, mais especificamente, essa tecnologia está sendo introduzida não somente em áreas de cultivo de agricultura familiar em geral, mas principalmente em assentamentos rurais. Percebe-se, desse modo, tratar-se de um tipo de produção que tende a incorporar a dimensão histórico-social e a considerar os valores culturais e de senso comum inerentes aos agricultores familiares (Costa Neto, 1999).

Embora a falta de informações oriundas de institutos de pesquisa possa ter contribuído para gerar dificuldades e fomentar experiências negativas de muitos produtores, essas não os fizeram esmorecer, pois eles são inovadores e experimentadores, desejosos de adotar novas práticas, buscando benefícios próprios e coletivos. Nos últimos cinqüenta anos, a inovação na agricultura tem sido impulsionada principalmente pela ênfase em altos rendimentos e no lucro da unidade produtiva. Apesar da continuidade dessa forte pressão econômica sobre a agricultura, muitos produtores convencionais estão preferindo fazer a transição para práticas que são mais consistentes ambientalmente e com o potencial de contribuir para a sustentabilidade da agricultura em longo prazo (Gliessman, 2000).

A transformação ou a substituição de um modelo de desenvolvimento para outro supõe um processo de transição que, em alguns momentos, caminha a passos lentos e, em outros, pode trazer mudanças bruscas e qualitativamente diferenciadas. Esse processo de transição significa a conversão de uma agricultura tradicional para uma agricultura ecológica e socialmente equilibrada, com base na sustentabilidade (Goméz, 1997).

Desse modo, o manejo do solo e das plantas, orientado pela agroecologia, pode se constituir numa promissora alternativa para obtenção de sementes de qualidade, sem comprometer a saúde dos agricultores e contribuindo para a preservação ambiental. Diversas práticas vêm sendo utilizadas com esta finalidade, entre elas citam-se a adubação orgânica e os biofertilizantes enriquecidos. No entanto, esses fatores de produção precisam ser avaliados especialmente quanto a adequação pelos produtores de semente de cebola, objetivando um sistema de produção sustentável.

A agricultura orgânica está adquirindo uma importância crescente no setor agrícola de diversos países, independente do seu grau de desenvolvimento. A superfície agrícola útil destinada a cultivos orgânicos no Brasil, em cinco anos passou de 120.000 para 400.000 ha, com perspectivas de aumentar 50\% ainda este ano. Um levantamento feito pela Federação Internacional de Agricultura Orgânica revela que 
o mercado mundial de produtos do gênero movimentou 23 bilhões de dólares, em 2003, e que seu consumo cresce a uma média de $30 \%$ ao ano. No Brasil, o setor movimenta 120 milhões de dólares, $30 \%$ dos quais vindos de exportações, valor este que confirma a importância crescente do setor, cuja taxa de crescimento não é igualada por nenhum outro setor de alimentos convencionais. De acordo com Schiedeck (2002), o mercado de alimentos produzidos sob a orientação agroecológica, sem utilização de agrotóxicos ou adubos minerais, tem aumentado em todo o mundo. Alguns dados indicam que esse segmento cresce anualmente cerca de $20 \%$ nos Estados Unidos, $40 \%$ na Europa e 50\% no Brasil e para comprovar tais índices, basta verificar a proliferação das feiras de produtores ecológicos nas cidades, o aumento dos espaços para esses produtos nas gôndolas das grandes redes de supermercados e os movimentos ambientalistas e de consumidores que buscam uma alimentação mais saudável.

A agroecologia como ciência apresenta várias dimensões: ecológica, econômica, social, cultural, política e ética. Nesse sentido e considerando a procura crescente por produtos orgânicos e a necessidade de sistemas de produção adequados ao cultivo de semente de cebola, o presente trabalho teve como objetivo fazer um estudo nos sistemas de produção de sementes de cebola convencional e agroecológico, indicando fatores que contribuam com o processo de implantação ou transição de um determinado sistema de produção, tornando-o economicamente viável, fazendo com que a propriedade agrícola constitua, para o agricultor e sua família, uma fonte de estabilidade econômica, bem estar e garantia de sustentabilidade,

\section{MATERIAL E MÉTODOS}

O estudo foi conduzido em propriedades que tradicionalmente cultivam sementes de cebola em sistemas de produção convencional e agroecológico, situadas nos municípios de Candiota e Hulha Negra, região geo-econômica de Bagé, sudoeste do Estado do Rio Grande do Sul, no ano agrícola 2003. O clima da região é mesotérmico, subtropical, com temperatura média anual de $17,6^{\circ} \mathrm{C}$ e umidade relativa do ar entre $75 \%$ e $85 \%$. Na Tabela 1 do apêndice, encontram-se indicados os elementos meteorológicos registrados no período de condução do estudo.
Foram instaladas unidades de amostragem correspondente aos sistemas de produção em lavouras de dois produtores em sistema convencional e dois em sistema agroecológico. Em uma das propriedades do sistema agroecológico, o estudo foi efetuado em duas áreas distintas e com manejos de cultivo diferentes.

Em cada lavoura, dos diferentes sistemas de produção, foram marcadas aleatoriamente seis unidades de amostragem, cada uma delas com dois metros ao longo da linha de produção, sendo a área correspondente a 1,6 m². O espaçamento entre linhas foi de $0,8 \mathrm{~m}$.

\section{SISTEMA CONVENCIONAL}

As propriedades nas quais foram efetuados os estudos do sistema convencional eram de produtores da empresa Hortec Sementes Ltda.

Esse sistema de produção utiliza mão de obra contratada sob remuneração financeira. Para o preparo do solo das áreas de produção, foram realizadas as operações de aração, gradagem e sulcagem. Todas as operações de preparo do solo foram mecanizadas.

A cultivar plantada no sistema convencional I foi Baia Periforme, em área de 4,5 ha, e no convencional II Bola Precoce, em área de 2,5 ha. Os bulbos da categoria registrados foram produzidos em Santa Catarina a partir de sementes básicas da EPAGRI. Nas duas áreas, o plantio foi realizado em junho de 2003. A semente produzida foi da categoria certificada.

A adubação utilizada foi composta da fórmula 5-30-15 (400 kg/ha), Uréia (200 kg/ha), Cal 40 (3,0 1/ha), Super boro (1,0 1/ha), Hortifós (18,0 1/ha), e Agrik 480 (6,0 1/ha). A adubação foi nos sulcos e em cobertura (40 dias após o plantio). Após o plantio, foram realizadas aplicações de defensivos químicos como Ridomil, de modo preventivo para controle do míldio (Peronospora destructor), na dose de 2,5 kg/ha, com intervalos de sete dias; Folicur PM, após o aparecimento dos primeiros sintomas de mancha púrpura (Alternaria porri), na dose de $1,0 \mathrm{~kg} / \mathrm{ha}$, com intervalos de 14 dias; Rovral, com a mesma indicação de Folicur, na dosagem de 150g/1001 de água; Dithane, também após o aparecimento dos primeiros sintomas de mancha púrpura (Alternaria porri) e míldio (Peronospora destructor), na dose de 3,0 kg/ha, com intervalos de sete dias e Karate 
Zeon, também após o aparecimento dos primeiros sintomas da trips do fumo (Trips tabaci), na dose de 100ml/ha, com intervalos de três dias, através de pulverizações. Também foram realizadas capinas para retirada de plantas invasoras.

No momento da colheita das sementes, porções de três unidades de amostragem foram colhidas pelo produtor, alterando a unidade.

\section{SISTEMA AGROECOLÓGICO E CARACTERIZAÇÃO DAS PROPRIEDADES}

As propriedades nas quais foram efetuados os estudos do sistema agroecológico eram de produtores da marca Bionatur Sementes e integrantes da Coperal (Cooperativa Regional dos Agricultores Assentados Ltda).

A mão de obra empregada na produção agroecológica é totalmente familiar. Para o preparo do solo das áreas de produção, foram realizadas operações com grade aradora e grade de dente, seguida do arado pica-pau para marcar os sulcos. Todas as operações de preparo do solo foram realizadas com tração animal.

A adubação utilizada foi composta de uma mistura de MB4 (composto de rocha - $100 \mathrm{~kg} / \mathrm{ha}$ ), fosfato (100 kg/ha) e composto Ecocitrus (adubo orgânico - 5000 kg/ha), incorporada nos sulcos. Após o plantio dos bulbos, foram realizadas três aplicações de calda bordaleza a $1 \%$, entre o plantio e a floração, e aplicações do biofertilizante, desde o plantio até o final do ciclo da cultura. A fabricação do biofertilizante (200 litros), foi a partir do Kit Supermagro, composto de sais de micronutrientes (boro, cobre, manganês), acrescido de 40 litros de esterco, 100 litros de água, quatro litros de leite e cinco quilos de açúcar ou mel. O tambor foi colocado em exposição ao sol para ajudar na fermentação e, a cada sete dias, era acrescentado um sal de micronutriente. $\mathrm{O}$ pH era mantido em torno de 6,5.

Também foram realizadas capinas para retirada de plantas invasoras.

\section{Propriedade I - Gleba 1}

A cultivar foi Bola Precoce, de 04 a 08 de julho de 2003, em área de 0,7 ha. Os bulbos da categoria certificados foram produzidos nas cidades de Canguçu e São José do Norte, a partir de sementes básicas da EPAGRI (produção convencional). Na resteva de melão, com preparo da área, e incorporação da adubação, foram feitos o plantio e a cobertura dos bulbos em consorcio com feijão. As aplicações do biofertilizante eram realizadas nas folhas com pulverizador costal e nas raízes através da água de irrigação, com intervalos de sete dias entre uma aplicação e outra. No momento da colheita da semente, porções de duas unidades de amostragem foram colhidas pelo produtor, alterando a unidade. A semente colhida foi da categoria certificada.

\section{Propriedade I - Gleba 2}

A cultivar foi Bola Precoce, de 08 a 10 de julho de 2003, em uma área de 0,3 ha. Os bulbos da categoria certificados foram produzidos nas cidades de Canguçu e São José do Norte, a partir de semente básica da EPAGRI (produção convencional). Na resteva de milho e feijão, com preparo da área foi feito o plantio com a incorporação da adubação e cobertura dos bulbos, um mês após o plantio. As aplicações do biofertilizante foram realizadas nas folhas com pulverizador costal e nas raízes através da água de irrigação, com intervalos de sete dias entre uma e outra. A semente colhida foi da categoria certificada.

\section{Propriedade II}

A cultivar foi Baia Periforme, de 08 a 12 de julho de 2003, em área de 0,7 ha. Os bulbos da categoria fiscalizados foram produzidos na cidade de Canguçu, a partir de semente, certificada da Bionatur (produção agroecológica). $\mathrm{Na}$ resteva de milho e amendoim, com preparo da área e incorporação da adubação, foram feitos o plantio e a cobertura dos bulbos quando a planta atingiu $10-15 \mathrm{~cm}$ de altura. As aplicações do biofertilizante foram realizadas somente nas folhas com pulverizador costal, com intervalos maiores entre uma aplicação e outra e menos regulares, em relação à propriedade I. No momento da colheita da semente, parte de uma unidade de amostragem foi colhida pelo produtor, alterando a unidade. A semente colhida foi da categoria fiscalizada.

\section{Colheita e Beneficiamento da Semente}

A colheita da semente foi manual e escalonada, de acordo com a maturação. A limpeza das umbelas para retirada das semente também foi manual. As sementes 
foram secas em exposição ao ar ambiente sobre telados de madeira, até que, ao serem comprimidas entre as mãos, se desprendessem das umbelas. A limpeza completou-se com o auxílio de um túnel de vento, durante dois minutos, para a retirada de impurezas menores. Cada amostra de 17,34 g foi passada no soprador com abertura de $1,8 \mathrm{~cm}$. Após, a semente e o descarte foram pesados. Então, foram acondicionadas em sacos de papel e armazenadas em câmara seca, com temperatura de $15^{\circ} \mathrm{C}$ e $55 \%$ de umidade relativa, para as avaliações posteriores. A semente nesse momento apresentava teor de água de $8 \%$ a $9 \%$.

\section{AVALIAÇÕES}

As variáveis estudadas nas unidades de amostragem foram:

- Massa de bulbo (g): obtido a partir da pesagem individual de uma amostra correspondente a $10 \%$ do total de bulbos implantados no sistema de produção agroecológico.

- Diâmetro de bulbo (mm): obtido a partir da medida do diâmetro individual de uma amostra correspondente a $10 \%$ do total de bulbos implantados no sistema de produção agroecológico.

- Número de bulbos por área: obtido pela contagem de todos os bulbos plantados por unidade de amostragem, sendo expresso em 1,6 $\mathrm{m}^{2}$.

- Número de hastes por bulbo: obtido pela contagem do número de hastes correspondentes a cada bulbo plantado por unidade de amostragem.

- Número de flores por umbela: obtido pela contagem do número de flores correspondente a três umbelas representativas de cada área de produção.

- Número de sementes por cápsula: obtido pela contagem do número de sementes de cada uma das cápsulas correspondentes a cada uma das três umbelas representativas de cada área de produção.

- Teor de água da semente: determinação realizada segundo o método da estufa a $105^{\circ} \pm 3^{\circ} \mathrm{C}$, sendo utilizadas 5,0g de sementes, de acordo com as Regras para Análise de Sementes RAS (Brasil, 1992).
- Rendimento de sementes (kg/ha): estimado a partir do peso da semente colhida por unidade de amostragem.

- Germinação (\%): realizada com quatro subamostras de 100 sementes e temperatura de $20^{\circ} \mathrm{C}$, sendo as avaliações realizadas conforme RAS (Brasil, 1992).

- Primeira contagem (\%): obtido a partir do material utilizado no teste de germinação. A primeira contagem foi realizada aos seis dias após o início do teste.

- Peso de 1000 sementes (g): obtido pela pesagem de oito subamostras de 100 sementes, segundo as determinações das RAS (Brasil, 1992).

- Envelhecimento acelerado (\%): o teste foi conduzido expondo a semente à temperatura de $42^{\circ} \mathrm{C} / 72$ horas a $100 \%$ de UR, de acordo com a AOSA (1983), seguindo o teste de germinação RAS (Brasil, 1992), com avaliação aos seis dias.

- Índice de velocidade de germinação em substrato: o teste foi conduzido conforme Nakagawa (1999), dentro do laboratório em ambiente controlado, em bandejas de poliestireno expandido de 200 células contendo substrato artificial (Plantmaxâ) e uma semente por célula. Foram utilizadas quatro subamostras de 25 sementes e realizadas contagens diárias até a estabilização da germinação, sendo encerrado o teste aos 12 dias.

- Velocidade de germinação em substrato (dias): o teste foi conduzido conjuntamente com o índice de velocidade de germinação em substrato e o cálculo determinado conforme Nakagawa (1999).

- Sanidade de semente (\%): avaliada pelo método do papel filtro, com quatro subamostras de 50 sementes incubadas à em temperatura de $25^{\circ} \pm 2^{\circ} \mathrm{C}$, por sete dias, com 12 horas de luz e 12 horas de escuro. Após, a semente foram examinadas individualmente sob microscópio estereoscópico.

- Custo de produção (R\$): obtido a partir das operações e utilização de insumos para os diferentes sistemas de produção.

Os dados foram apresentados através de tabelas de distribuições de freqüências e medidas descritivas que foram executadas pelo programa WinStat - Sistema de Análise Estatística para Windows - Versão Beta (Machado e Conceição, 2005). 


\section{RESULTADOS E DISCUSSÃO}

\section{SISTEMA CONVENCIONAL}

As distribuições de freqüências do número de hastes por bulbo, nas duas propriedades do sistema de produção convencional, são apresentadas na Tabela 1. O número de hastes por bulbo variou de zero a 13 , sendo as maiores freqüências observadas para cinco (14\%), sete (18\%) e dez $(14 \%)$ hastes na propriedade I e três e cinco (ambas $19 \%)$, na propriedade II.

TABELA 1 - Número de hastes por bulbo de cebola, em duas propriedades do sistema de produção convencional.

\begin{tabular}{ccc}
\hline \multirow{2}{*}{$\begin{array}{c}\text { Quantidade } \\
\text { de Hastes }\end{array}$} & \multicolumn{2}{c}{ Quantidade de Bulbos } \\
\cline { 2 - 3 } & Propriedade I & Propriedade II \\
\hline 0 & 0 & 0 \\
1 & 0 & 0 \\
2 & 1 & 1 \\
3 & 3 & 10 \\
4 & 3 & 5 \\
5 & 7 & 10 \\
6 & 6 & 6 \\
7 & 9 & 7 \\
8 & 6 & 4 \\
9 & 3 & 3 \\
10 & 7 & 3 \\
11 & 1 & 2 \\
12 & 0 & 1 \\
13 & 3 & 0 \\
\hline Total & 49 & 52 \\
\hline Média $(\bar{x})$ & 7,18 & 6,16 \\
\hline Desvio $(s)$ & 2,65 & 2,44 \\
\hline
\end{tabular}

Um dos componentes de maior importância no rendimento de sementes é o total de flores por umbela, que pode ser de até 2.000 flores (Castellane et al., 1990). Observa-se, nas distribuições de frequiências para o número de sementes por cápsula (Tabelas 2 e 3 ), que os valores máximos de flores por umbela foram de 549 e 587, nas propriedades I e II, respectivamente, valores muito inferiores ao limite máximo esperado. Verifica-se também que a maioria das cápsulas (51\%, na propriedade I, e 67\%, na propriedade II) apresentaram de duas a três sementes. De forma similar, Sampaio et al. (1998) observaram que cápsulas que continham três sementes ocorreram com maior freqüência (28\%). Esses resultados demonstram que o mecanismo da polinização não tem sido eficiente na produção de sementes de cebola e pode ser um dos principais causadores da baixa produtividade.

De acordo com Castellane et al. (1990), pode haver a formação máxima de seis sementes por flor (cápsula), desde que a polinização seja eficiente, pois a cebola possui ovário trilocular, com dois óvulos em cada loja. Pode-se observar nas distribuições de freqüências para a quantidade de sementes por flor que poucas flores expressaram seu potencial produtivo máximo de seis sementes (Tabelas $2 \mathrm{e}$ 3). A quantidade mais freqüente (moda) de sementes por flor ficou em torno de três, para a maioria das umbelas.

Segundo Sampaio et al. (1998), a produtividade média de sementes obtida na região não tem ultrapassado 300$350 \mathrm{~kg} / \mathrm{ha}$, e que, para o autor, é possível obter-se valores de até $1000 \mathrm{~kg} / \mathrm{ha}$. A maior produtividade média foi calculada para a propriedade I $(943,00 \mathrm{~kg} / \mathrm{ha})$, que se encontra próxima do limite máximo de produção para esse sistema. Bem abaixo desse limite está a propriedade II com $470,67 \mathrm{~kg} / \mathrm{ha}$.

Os resultados obtidos para as variáveis analisadas em laboratório encontram-se na Tabela 4, onde foi observado que a maior porcentagem de germinação foi obtida pela propriedade II (90\%). O peso de 1000 sementes foi maior para a propriedade I $(3,17 \mathrm{~g})$, o que em parte explica a maior produtividade obtida por esse sistema. O maior vigor de sementes para as variáveis analisadas foi obtido pela propriedade II, o que, de acordo com Carvalho e Nakagawa (2000), pode ser explicado pelo fato de as sementes não se formarem todas ao mesmo tempo, de maneira que as últimas a se formarem são normalmente menores ou de menor densidade, resultando em sementes menos vigorosas. Para as variáveis índice de velocidade de emergência e velocidade de emergência não ocorreram diferenças entre as propriedades. 
TABELA 2 - Quantidade de sementes por flor nas três umbelas de cebola correspondentes à propriedade I do sistema de produção convencional.

\begin{tabular}{c|ccc|c|c}
\hline \multirow{2}{*}{$\begin{array}{c}\text { Quantidade de } \\
\text { semente }\end{array}$} & \multicolumn{3}{|c|}{ Quantidade de Flores } & \multirow{2}{*}{ Total } & \multirow{2}{*}{ Média } \\
\cline { 2 - 4 } & Umbela 1 & Umbela 2 & Umbela 3 & & \\
\hline 0 & 1 & 5 & 16 & 22 & 7,33 \\
1 & 1 & 12 & 47 & 60 & 20,00 \\
2 & 15 & 24 & 161 & 200 & 66,67 \\
3 & 35 & 39 & 238 & 312 & 104,00 \\
4 & 44 & 76 & 71 & 191 & 63,67 \\
5 & 33 & 111 & 14 & 158 & 52,67 \\
6 & 22 & 42 & 2 & 66 & 22,00 \\
\hline Total & 151 & 309 & 549 & 1.009 & 336,33 \\
\hline
\end{tabular}

TABELA 3 - Quantidade de sementes por flor nas três umbelas de cebola correspondentes à propriedade II do sistema de produção convencional.

\begin{tabular}{c|ccc|c|c}
\hline \multirow{2}{*}{$\begin{array}{c}\text { Quantidade de } \\
\text { semente }\end{array}$} & \multicolumn{3}{|c|}{ Quantidade de Flores } & \multirow{2}{*}{ Total } & \multirow{2}{*}{ Média } \\
\cline { 2 - 4 } & Umbela 1 & Umbela 2 & Umbela 3 & & \\
\hline 0 & 2 & 93 & 61 & 156 & 52,00 \\
1 & 21 & 75 & 48 & 144 & 48,00 \\
2 & 184 & 186 & 165 & 535 & 178,33 \\
3 & 231 & 157 & 210 & 598 & 199,33 \\
4 & 79 & 59 & 92 & 230 & 76,67 \\
5 & 14 & 8 & 10 & 32 & 10,67 \\
6 & 2 & 1 & 1 & 4 & 1,33 \\
\hline Total & 533 & 579 & 587 & 1.699 & 566,33 \\
\hline
\end{tabular}


TABELA 4 - Média e desvio padrão de sementes de cebola para as variáveis: germinação, primeira contagem, envelhecimento acelerado, peso de 1000 sementes, índice de velocidade de germinação e velocidade de germinação, das propriedades I e II do sistema de produção convencional.

Variável
Propriedade I

\section{Média $(\bar{x})$ Desvio padrão $(s)$}

Propriedade II Média $(\bar{x})$ Desvio padrão $(s)$

\begin{tabular}{lcccc}
\hline Germinação $(\%)$ & 85 & 3,69 & 90 & 6,81 \\
Primeira contagem $(\%)$ & 79 & 4,46 & 72 & 5,28 \\
Envelhecimento acelerado (\%) & 73 & 6,25 & 87 & 5,46 \\
$\begin{array}{l}\text { Peso de } 1000 \text { sementes }(\mathrm{g}) \\
\text { Índice de velocidade de }\end{array}$ & 3,17 & 0,06 & 2,91 & 0,08 \\
germinação & 2,69 & 0,47 & 2,85 & 0,21 \\
Velocidade de germinação & 7,85 & 0,79 & 7,21 & 0,22 \\
\hline
\end{tabular}

Com relação à análise da sanidade das sementes foi observado que a propriedade I apresentou maior incidência total de fungos $(26,9 \%)$, enquanto que na propriedade II a incidência foi de 21,3\%. Para as propriedades I e II, o fungo de maior incidência foi Stemphylium, com 18,9\% e $14,6 \%$, respectivamente. Entretanto, um maior número de espécies fúngicas foi observado na propriedade II, embora os mesmos tenham ocorrido em menores porcentagens de incidência (Tabela 5). Destaca-se que fungos patogênicos, como Alternaria porri e Fusarium sp. não foram detectados nas sementes da propriedade I. Também foi observado maior descarte nas sementes obtidas na propriedade II, provavelmente devido aos fungos $A$. porri e Fusarium sp, normalmente responsáveis por redução do tamanho e peso de semente e reflexos negativos na qualidade fisiológica das mesmas.
TABELA 5 - Incidência de fungos associados a sementes de cebola (Allium cepa $\mathbf{L}$.) produzidas nas duas propriedades do sistema de produção convencional.

\begin{tabular}{lcc}
\hline \multirow{2}{*}{ Fungos } & \multicolumn{2}{c}{ Incidência de fungos (em \%) } \\
\cline { 2 - 3 } & Propriedade I & Propriedade II \\
\hline $\begin{array}{l}\text { Alternaria } \\
\text { alternata }\end{array}$ & 7,0 & 1,8 \\
Alternaria porri & - & 0,9 \\
Aspergillus & - & 0,6 \\
flavus & - & 2,8 \\
Fusariumsp & 1,0 & 0,6 \\
Penicilliumsp & 18,9 & 14,6 \\
Stemphylium $s p$ & 26,9 & 21,3 \\
\hline Total & &
\end{tabular}




\section{SISTEMA AGROECOLÓGICO}

A distribuição de frequiências do número de hastes por bulbos para as duas propriedades do sistema agroecológico encontra-se na Tabela 6. O número de hastes por bulbo variou de zero a nove, sendo de maior freqüência os bulbos que apresentaram entre duas e cinco hastes. A propriedade I apresentou uma média de 4,3 hastes por bulbo, sendo $68 \%$ dos bulbos com três a cinco hastes.

Os resultados relativos à variável quantidade de bulbos e sementes por cápsula de cada propriedade são apresentados nas Tabelas 6 a 7 . A quantidade total de flores das umbelas amostradas nas propriedades foi de 1.204, 1.110 e 1.162, respectivamente, para as propriedades I - gleba 1 e 2 e propriedade II. Foram mais frequientes as flores que apresentaram entre duas e três sementes, e o número máximo foi de seis sementes por flor.

Na Tabela 8, são apresentados médias $(\bar{x})$ e desvios padrões $(s)$ para a variável quantidade de sementes por cápsula, nas três umbelas amostradas em cada propriedade. As características de simetria e mesocurtose observadas para essa variável são típicas da distribuição normal. Considerando que a forma da distribuição da quantidade de sementes se assemelha à forma da distribuição normal, é razoável esperar que essa variável apresente propriedades da normal. Uma propriedade importante da distribuição normal se refere às proporções de valores que se encontram entre a média e o desvio padrão: no intervalo entre a média mais e menos um desvio padrão $(\mu \pm \sigma)$ esta proporção é de 0,6825 , entre a média mais e menos dois desvios padrões $(\mu \pm 2 \sigma$ é de 0,9544 e entre a média mais e menos três desvios padrões $(\mu \pm 3 \sigma$ é de 0,9975 (Freund e Simon, 2000). Sendo assim, pode-se esperar que aproximadamente $68 \%$ das flores apresentem quantidade de sementes no intervalo $\bar{x} \pm s$ e $95 \%$ no intervalo $\bar{x} \pm 2 s$. Por exemplo, na propriedade I - gleba 1, em torno de $68 \%$ das flores teriam entre 1,89 e 3,89 sementes, e $99 \%$ das flores teriam entre 0,89 e 4,89 ( 1 a 5 sementes).

A maior produtividade média observada foi para a propriedade I - gleba $2(711,67 \mathrm{~kg} / \mathrm{ha})$, em segundo lugar a propriedade I - gleba $1(612,5 \mathrm{~kg} / \mathrm{ha})$, tendo a propriedade II obtido a menor produtividade $(448,8 \mathrm{~kg} / \mathrm{ha})$. As produtividades mais elevadas, observadas na propriedade I - glebas 1 e 2, possivelmente tenham resultado do manejo diferenciado adotado pelo produtor. Nessas propriedades, as aplicações do biofertilizante foram efetuadas em períodos regulares via pulverização foliar e na raiz, pela água de irrigação (fertirrigação), o que confirma a tese de Camargo (1975) de que a utilização de adubos foliares substitui parcialmente a adubação radicular, em $20 \%$ a $25 \%$, podendo ser utilizada em várias pulverizações.

Assim, os biofertilizantes têm sido empregados na agricultura ecológica como adubo foliar para aumentar a resistência contra pragas e doenças. Além disso, o processo de produção é bastante simples e por isso é viável sua produção na propriedade, desde que haja esterco disponível (Penteado,1999). Métodos alternativos de adubação, controle de doenças, pragas e plantas indesejáveis têm sido muito estudados e, dentro dessa linha de pesquisa, destacase o uso de matéria orgânica, através tanto de sua incorporação ao solo como de sua transformação para uso posterior na forma de biofertilizantes (Khatounian, 1997; Bettiol et al., 1997).

Ressalta-se também a maior experiência deste produtor da propriedade I, que investe nesse sistema de produção por um período de tempo maior que o produtor da propriedade II. A diferença de produtividade entre as propriedades I e II também pode ser atribuída às práticas culturais utilizadas pelo produtor em áreas distintas. Para a área onde foi implantado o sistema agroecológico da propriedade I - gleba 2, ou seja, o de maior produtividade, a cobertura dos bulbos foi realizada um mês após o plantio.

Considerando que para a produção de um hectare de semente de cebola são utilizadas três toneladas de bulbos com massa média de 100 g cada (30.000 bulbos), que cada bulbo produz em média 4,3 hastes (obtida no estudo) e que cada haste produzirá uma umbela com 1000 flores, estimase uma produção de 129.000.000 flores por hectare, onde cada flor poderá produzir até seis sementes, totalizando 774.000.000 sementes. Como 1000 sementes de cebola pesam 3,06 g, ter-se-á, então, um potencial de produção de $2.368 \mathrm{~kg}$ de sementes por hectare.

As produtividades médias observadas neste estudo, para as duas propriedades do sistema agroecológico, encontramse bem abaixo do seu potencial, (menos de 30\%). Isto pode ser explicado pelo fato de o número médio de flores por umbela $(386,22)$ e o número médio de sementes por cápsula $(3,01)$ das duas propriedades estarem muito distantes do seu potencial máximo. Essa observação sugere que a falta 
de polinização pode ser um dos principais fatores comprometedores desse componentes de rendimento, sendo responsável pelas baixas produtividades na região e que esse problema poderia ser minimizado com o aumento do número de agentes polinizadores nas áreas de produção.

Com relação à utilização de adubos orgânicos, que se constituem em outro componente de rendimento fundamental para esse sistema de produção, Lanna et al. (1994) afirmam que no Brasil algumas fontes de adubos orgânicos, com e sem adição de nutrientes, têm sido testadas em diferentes culturas. Isso confirma a importância que vem sendo dada à escolha do adubo orgânico, com vistas ao aumento da produtividade e sua contribuição relevante na melhoria da qualidade das hortaliças, bem como do composto humificado ou curado que, sendo rico em nutrientes que passaram parcialmente da forma orgânica para a forma mineral, assimilável pelas raízes e com maior teor coloidal, atua como fertilizante e é responsável pela capacidade melhoradora do solo (Barreto, 1985).

Para as variáveis analisadas em laboratório, foi observado que a maior porcentagem de germinação foi obtida pela propriedade I - gleba 1 (92\%), e a menor pelas propriedades I - gleba 2 e propriedade II ( $85 \%)$. O peso de 1000 sementes foi maior para a propriedade I - gleba 2 $(3,15 \mathrm{~g})$, o que em parte explica a maior produtividade obtida por esse sistema. O maior vigor de semente para as variáveis analisadas e de acordo com a Tabela 9, foi obtido na propriedade I - gleba 1. Essas diferenças podem estar associadas à experiência do produtor e aos tratos culturais utilizados, como mencionado anteriormente.

Em relação à análise sanitária da semente foi observado que a propriedade I - gleba 2 apresentou maior incidência

TABELA 6 - Quantidade de hastes por bulbo de cebola, média e desvio padrão em duas propriedades do sistema de produção agroecológico.

Quantidade de Bulbos

\begin{tabular}{cccc} 
Quantidade de Hastes & $\begin{array}{c}\text { Propriedade I } \\
\text { Gleba 1 }\end{array}$ & $\begin{array}{c}\text { Propriedade I } \\
\text { Gleba 2 }\end{array}$ & Propriedade II \\
\hline 0 & 0 & 0 & 3 \\
1 & 3 & 1 & 6 \\
2 & 13 & 10 & 14 \\
3 & 9 & 20 & 24 \\
4 & 7 & 15 & 14 \\
5 & 14 & 17 & 11 \\
6 & 9 & 4 & 7 \\
7 & 5 & 3 & 2 \\
8 & 3 & 2 & 1 \\
9 & 1 & 1 & 2 \\
\hline Total & 64 & 74 & 85 \\
\hline Média $(\bar{x})$ & 4,31 & 4,50 & 4,36 \\
\hline Desvio $(s)$ & 1,99 & 1,66 & 1,70 \\
\hline
\end{tabular}


TABELA 7 - Quantidade de semente, por flor nas três umbelas de cebola correspondentes a propriedade I do sistema de produção agroecológico.

\begin{tabular}{c|ccc|c|c}
\hline \multirow{2}{*}{$\begin{array}{c}\text { Quantidade de } \\
\text { sementes }\end{array}$} & \multicolumn{3}{|c|}{ Quantidade de Flores } & \multirow{2}{*}{ Total } & \multirow{2}{*}{ Média } \\
\cline { 2 - 5 } & Umbela 1 & Umbela 2 & Umbela 3 & & 4,67 \\
1 & 0 & 5 & 9 & 14 & 73 \\
2 & 6 & 37 & 30 & 313 & 104,33 \\
3 & 100 & 108 & 105 & 493 & 164,33 \\
4 & 185 & 143 & 165 & 262 & 87,33 \\
5 & 135 & 39 & 88 & 45 & 15,00 \\
6 & 18 & 6 & 21 & 4 & 1,33 \\
\hline Total & 3 & 0 & 1 & 1.204 & 401,33 \\
\hline
\end{tabular}

TABELA 8 - Média e desvio padrão da variável quantidade de semente por cápsula de cebola, em duas propriedades do sistema de produção agroecológico.

\begin{tabular}{lccc}
\hline \multicolumn{1}{c}{ Propriedade } & Umbela & Média $(\bar{x})$ & Desvio padrão $(s)$ \\
\hline \multirow{3}{*}{ Propriedade I } & 1 & 3,15 & 0,88 \\
Gleba 1 & 2 & 2,57 & 0,95 \\
& 3 & 2,86 & 1,07 \\
\hline \multirow{3}{*}{ Propriedade I } & Geral & 2,89 & 1,00 \\
Gleba 2 & 1 & 2,55 & 0,82 \\
& 2 & 3,23 & 1,12 \\
& 3 & 3,18 & 1,30 \\
\cline { 2 - 4 } & Geral & 2,97 & 1,12 \\
Propriedade II & 1 & 3,00 & 1,10 \\
& 2 & 3,14 & 1,38 \\
& 3 & 3,46 & 1,33 \\
\hline
\end{tabular}


TABELA 9 - Média e desvio padrão de semente de cebola para as variáveis: germinação, primeira contagem, envelhecimento acelerado, peso de 1000 sementes, índice de velocidade de germinação e velocidade de germinação, da propriedade I - glebas 1 e 2 , e da propriedade II do sistema de produção agroecológico.

\begin{tabular}{|c|c|c|c|c|c|c|}
\hline \multirow{2}{*}{ Variável } & \multicolumn{2}{|c|}{ Propriedade I - Gleba 1} & \multicolumn{2}{|c|}{ Propriedade I - Gleba 2} & \multicolumn{2}{|c|}{ Propriedade II } \\
\hline & Média $(\bar{x})$ & $\begin{array}{c}\text { Desvio padrão } \\
(s)\end{array}$ & Média $(\bar{x})$ & Desvio padrão $(s)$ & Média $(\bar{x})$ & Desvio pad \\
\hline Germinação (\%) & 92 & 4,97 & 85 & 12,31 & 85 & 6,81 \\
\hline Primeira contagem $(\%)$ & 90 & 5,28 & 78 & 15,85 & 72 & 5,47 \\
\hline Envelhecimento acelerado (\%) & 87 & 5,46 & 72 & 15,36 & 84 & 5,13 \\
\hline Peso de 1000 sementes (g) & 2,91 & 0,08 & 3,15 & 0,12 & 3,12 & 0,16 \\
\hline $\begin{array}{l}\text { Índice de velocidade de } \\
\text { germinação }\end{array}$ & 2,85 & 0,21 & 2,04 & 0,19 & 2,03 & 0,28 \\
\hline Velocidade de germinação & 7,21 & 0,22 & 8,86 & 0,98 & 8,39 & 0,74 \\
\hline
\end{tabular}


total de fungos $(81 \%)$, e que a menor foi na mesma propriedade, gleba $1(21,6 \%)$. Entre as espécies de fungos detectadas, as que apresentaram maior incidência foram: Alternaria alternata $(27,1 \%)$, Penicillium (21,9\%) e Aspergilus flavus $(16,1 \%)$, todas na propriedade II (Tabela $5)$.

Observa-se também que nas sementes produzidas na propriedade II foram encontradas três espécies de fungos não detectadas nas sementes da propriedade I - glebas $1 \mathrm{e}$ 2 (Alternaria porri, Helmintosporium sp. e Rhizopus sp.). As doenças de maior incidência na cebola são míldio (Peronospora destructor), alternaria (Alternaria porri), raiz rosada (Pyrenochaeta terrestris) e mais recentemente a antracnose foliar (Colletotrichum gloesporioides sp. сераe) (ICEPA-SC, 2005). Dessas, a Alternaria porri é um dos principais patógenos, responsável por reduções de rendimento do cultivo e de qualidade de semente.

\section{CONSIDERAÇÕES GERAIS}

Embora o objetivo deste estudo não tenha sido traçar um comparativo entre os diferentes sistemas de produção, algumas considerações podem ser feitas.

A produção de semente de cebola, em sistema convencional, é realizada em grandes extensões, com a utilização de defensivos químicos, tanto para a prevenção quanto para a erradicação de pragas e doenças, enquanto que, no sistema agroecológico, é efetuada em pequenas propriedades, de forma diversificada e sem a utilização de defensivos químicos, pois é baseada no tratamento preventivo e não curativo. Entretanto, apesar dessas diferenças, é possível produzir semente de cebola em ambos os sistemas, com a mesma qualidade fisiológica e com potencial produtivo semelhante.

Ainda que o sistema de produção convencional tenha, em média, maior produtividade e, conseqüientemente, maior margem de lucro, o custo de produção para o sistema agroecológico é menor; de modo que a transição do sistema convencional para o agroecológico é possível e, sob o ponto de vista da segurança ambiental, é até desejável.

O maior preço do produto final no sistema de produção agroecológico se deve ao fato de os riscos também serem maiores.

\section{CONCLUSÕES}

- A produção de sementes de cebola através do sistema de produção agroecológico é economicamente viável e ecologicamente sustentável.

- Pode-se considerar que o potencial de produção e qualidade fisiológica da semente de cebola agroecológica e convencional sejam similares. A produção de semente de cebola em ambos os sistemas alcança em média $30 \%$ do seu potencial.

- A variável quantidade de flores por umbela pode ser considerado o componente principal da produção de semente de cebola.

\section{REFERÊNCIAS}

ASSOCIATION OF OFFICIAL SEED ANALYSTS - AOSA. Seed vigour testing handbook. East Lansing, 1983.93 p. (Contribution, $32)$.

BARretto, D. X. Composto Orgânico. In: Prática em Agricultura Orgânica. São Paulo: Ícone Ed. Ltda, 1985. p. 51-63.

BETTIOL, W.; TRACH, R.; GALVÃO, J.A.H. Controle de doenças de plantas com biofertilizantes. Jaguariúna: EMBRAPA-CNPMA, 1997. 22p. (EMBRAPA-CNPMA. Circular Técnica, 02).

BRASIL. Ministério da Agricultura e Reforma Agrária. Regras para Análise de Sementes. Brasília: SNDA/DNDV/CLAV, 1992. 365p.

CAMARGO, P. N. D. Manual de Adubação Foliar. São Paulo: Herba, 1975.

CARVALHO, N. M. e NAKAGAWA, J. Sementes: Ciência, tecnologia e produção. Jaboticabal: FUNEP, 2000.

CASTELlANE, P. D.; NICOLOSI, W. M.; HASEGAWA, M. Produção de sementes de hortaliças. Jaboticabal, FCAV/Funep, 261p. 1990.

COSTA NETO, C. Agricultura Sustentável, Tecnologias e Sociedade. In: CARVALHO COSTA, L.F. et al. (org.) Mundo Rural e Tempo Presente. Rio de Janeiro: Mauad, 1999.

FREUND, J.E., SIMON, G.A. Estatística Aplicada. Economia, Administração e Contabilidade. 9.ed., Porto Alegre: Bookman, 2000. 404p.

GARCIA, A. Versão preliminar de um Programa Estadual de Produção e Comercialização de Bulbos e Sementes de Cebola. EMBRAPA/IPAGRO/MARA/EMATER. 68p, 1990. (Publicação avulsa). 
GLIESSMAN, S. R. Agroecologia. Processos ecológicos em agricultura sustentável. Porto Alegre: Universidade Federal do Rio Grande do Sul - UFRGS, 2000. 653p.

GOMÉZ, H. W. Desenvolvimento sustentável, agrícola e capitalismo. In: Desenvolvimento sustentável. Necessidade e/ou disponibilidade?. Santa Cruz do Sul: Nobel - UNISC, 1997. p. 6577.

ICEPA-SC. Informes conjunturais sobre a cultura da cebola. Disponível em:

<http://www.icepa. com.br>. Acesso as 14:20h em: 18 out. 2005.

KHATOUNIAN, C. A. Ciclo de Palestras sobre Agricultura Orgânica, 2a . Ed. São Paulo: Fund. Cargill, 1997, 149 p.

LANNA, F.C.A.; ABREU, C. L.; ABREU, J. G.; SILVA, V. Resposta de cultivares de melancia cultivadas sob adubação química e orgânica. Horticultura, v.12, n.1, p.85, 1994.
LORENZON, M. C. A.; MARTINHO, M. R. Comportamento das abelhas africanizadas (Apis mellifera L.) quando aprisionadas em ensaios de polinização. Pesquisa Agropecuária Brasileira, Brasília, v. 29, n. 11, p. 1685-1690, nov. 1994.

MACHADO, A.A.; CONCEIÇÃO, A.R. WinStat - Sistema de Análise Estatística para Windows. Versão Beta. Universidade Federal de Pelotas, 2005.

NAKAGAWA, J. Testes de vigor baseados no desempenho das plântulas. In: KRZYZANOWSKI, F.C.; VIEIRA, R.D.; FRANÇANETO, J.B. Vigor de sementes: conceitos e testes. Londrina: ABRATES, 1999, cap. 2, p. 1-21.

SAMPAIO, T. G.; SAMPAIO, N. V.; SOARES, P. F. Estudo de componentes do rendimento na produção de sementes de cebola (Allium cepa L.). Revista Científica Rural, Bagé, v. 3, n. 1, p. 1-7, 1998.

SCHIEDECK, G. Ambiência e resposta agronômica de meloeiro (Cucumis melo L.) cultivado sob adubação orgânica em ambiente protegido. Pelotas. 100p. Tese (Doutorado em Agronomia Produção Vegetal) - Faculdade de Agronomia 